\title{
BIOPOLÍTICA: A QUESTÃO DAVIOLÊNCIA DOMÉSTICA E OS CORPOS DA VIDA NUA
}

\author{
Rosane Cristina de Oliveira ${ }^{*}$ \\ Eliane Cristina Tenório Cavalcanti ${ }^{\dagger}$
}

\section{Resumo}

O presente artigo tem o objetivo investigar algumas formas que o Estado contemporâneo utiliza para promove intervenções biopolíticas acerca da violência contra mulher. Para isso, adotou-se o referencial teórico de Michel Foucault e Giorgio Agamben. Inicialmente será apresentado o entendimento foucaultiano a respeito da biopolítica, e a construção de Agamben estabelecida a partir da concepção de homo sacer e vida nua, no sentido de realiza-se uma aproximação das construções dos dois autores, evidenciando as principais concepções em que uma se mostra complementar à outra para então se pensar na questão da violência contra mulher, aqui percebida como vida nua. A seguir, busca-se a noção de refugo humano proposta por Bauman para compreender as condições sociais e de vida das mulheres em situação de violência, exclusão social e vulnerabilidade, pretendendo-se assim que elas possam ser lidas à luz dessas categorias. Finalmente, apresenta-se a lei do Feminicídio como ação biopolítica contemporânea. Palavras-chave: Biopolítica; vida nua; violência contra a mulher.

\section{BIOPOLYTICS: THE QUESTION OF DOMESTIC DAVOLENCE AND THE BODIES OF LIFE}

\begin{abstract}
This article aims to investigate ways in which the contemporary biopolitics State promotes interventions about violence against women in society To this end, we will adopt the theoretical framework of Michel Foucault and Giorgio Agamben. After the presentation of Foucault's understanding of biopolitics, and the construction of Agamben formed from homo design sacer, bare life, carried out an approximation of the conceptions of the two authors, highlighting the main points in which a sample is complementary the other to think about the issue of violence against women, here perceived as bare life. Next, search the notion of human waste and disposal, proposed by Bauman, to understand that the social and living conditions of women in situations of violence, social exclusion and vulnerability and are intended so that they can be read in light of these categories. Finally, it presents the law of Femicide as contemporary biopolitics action.
\end{abstract}

Keywords: Biopolitics; bare life; violence against women

\footnotetext{
* Professora do Programa de Pós-Graduação em Humanidades, Culturas e Artes da Unigranrio rosane.oliveira@unigranrio.br.

$\dagger$ Mestranda do Programa de Pós-Graduação em Humanidades, Culturas e Artes da Unigranrio eliane.cavalcanti@hotmail.com.
} 


\section{Introdução}

A violência contra a mulher é um fenômeno múltiplo e complexo que tem destacado importantes discussões teórico-filosóficas e questionamentos ético-políticos. Acredita-se que a questão pode ser considerada como um fenômeno coletivo, e por isso torna-se alvo da tecnologia do biopoder. A violência a contra mulher interessa ao biopoder, e, assim segue a ação biopolitica possibilitando a ação estatal em direção a mecanismos reguladores da população, a fim de coibir esse tipo de violência. É possível que a escolha de estratégias biopolíticas que privilegiem o enfrentamento à referida violência possam operar como dispositivos de intervenção que visem à maximização da vida e sua potencialidade enquanto unidade produtiva. Nesse sentido, ao focarrmos a administração da vida pelo Estado, pretendemos buscar uma aproximação da questão do feminicídio ante a esse entendimento.

A estrutura desse texto será apresentada a partir de três subtópicos. O primeiro é dedicado a uma breve apresentação da concepção de Foucault a respeito da biopolítica. Em sequência, será feita uma aproximação da noção de biopolitica em Agambem com a proposta foucaultiana para perceber os pontos de convergência entre os dois autores. A seguir recorre-se a uma figura do direito romano, o homo sacer, o modelo paradigmático de produção e justificativa da vida nua no contexto da estrutura jurídica e política do ocidente marcado pelo poder soberano e pelo estado de exceção para pensar a questão da mulher em estado de violência. $O$ homo sacer exemplifica como, através de sua exclusão, a vida nua é incluída na política. Posteriormente, busca-se a noção de resíduo humano, propostas por Bauman, entendendo que as condições sociais e de vida das mulheres em situação violência podem ser lidas à luz dessa categoria. Finalmente, apresenta-se a lei do Feminicídio como ação biopolítica contemporânea. Já que essa lei criou como modalidade de homicídio qualificado - o homicídio de mulher quando ocorre por violência doméstica e familiar ou menosprezo e discriminação por sexo.

\section{Do poder soberano a biopolítica}

Por muito tempo, explica Foucault (1997), o poder soberano possuiu como uma das principais características o direito de vida e morte. Contudo, este não era utlizado pelo soberano com relação aos seus súditos em termos absolutos ou de maneira incondicional, mas exclusivamente em situações em que o soberano encontrasse RPI Revista de Pesquisa Interdisciplinar, Cajazeiras, v. 1, n. 1, 33-46, jan/jul. de 2017. 
ameaçada sua própria existência. Desse modo, este direito era condicionado à defesa do soberano e também à sua sobrevivência, era o direito de causar a morte ou de deixar viver. Esta figura jurídica estabeleceu relações com uma forma histórica de sociedade em que o poder era exercido, principalmente, como instância de confisco, como um dispositivo de subtração, como o direito de se apropriar de uma parcela das riquezas. Com o advento da modernidade, o confisco tendeu a não ser mais o modo principal de exercício do poder, mas somente uma parte com funções de controle, vigilância, maximização e organização das potências submetidas a um poder destinado a produzir forças, a fazê-las aumentar e a ordená-las mais do que a barrá-las ou destruí-las. A morte, que se justificava no direito do soberano de se defender ou solicitar que o defendessem, surge depois como o simples reverso do direito do corpo social de assegurar sua própria vida.

Foucault (1997, p. 131) afirma que foram duas as principais formas que desenvolveram efetivamente o poder sobre a vida a partir do século XVII. A primeira se centrou no corpo-máquina, que teve como finalidade o seu adestramento, a ampliação de suas aptidões, a utilização de suas forças visando o crescimento paralelo de sua utilidade. As disciplinas como dispositivos de poder asseguravam o cumprimento dessas metas. A segunda forma de exercer o poder sobre a vida se constituiu por volta da metade do século XVIII e centralizava-se no corpo-espécie, no corpo como base de sustentação dos processos biológicos: os nascimentos e a mortalidade, o período de duração da vida, o nível de saúde, a longevidade. Tais processos são assumidos por meio de uma série de intervenções e controles reguladores, por meio de uma biopolítica da população. As disciplinas do corpo e formas de regulação da população integram os dois pólos em torno dos quais se expandiu a organização do poder sobre a vida.

Essa forma de organização do poder teve algumas consequências que não podem ser subestimadas. Dentre elas, destacamos, inicialmente, a ruptura que se produziu no estatuto do discurso científico. O novo modo de relacionar a história e a vida (que localiza a vida fora da história, como suas imediações biológicas, e, ao mesmo tempo, dentro da historicidade humana, infiltrada pelo saber e pelo poder) permitiu que a questão do significado do humano fosse colocada, possibilitando o surgimento das ciências humanas. Disto decorre a surgimento das tecnologias políticas que, a partir de então, serão investidas sobre o corpo, a saúde, os modos de se alimentar e de morar, as condições de sobrevivência em todo o espaço da existência. Uma outra consequência do biopoder é a importância crescente assumida pela atividade da norma, às expensas do 
sistema jurídico da lei. Um poder que tem a função de se encarregar da vida tem necessidade de mecanismos contínuos, reguladores e corretivos. Não se trata mais de colocar a morte em ação no campo da soberania, mas de distribuir os vivos em um plano de valor e utilidade. A lei funciona, nesta nova organização, cada vez mais como norma. A instituição judiciária se integra cada vez mais a um contínuo de aparelhos (administrativos e outros) cujas funções são, principalmente, reguladoras. As disciplinas difundem o discurso da regra, não da regra jurídica oriunda da soberania, mas o da regra "natural", ou seja, da norma. O horizonte teórico deixa de ser o do direito e passa a ser o das ciências humanas. Uma sociedade normalizadora é, portanto, o efeito histórico de uma tecnologia de poder centrada na vida (FOUCAULT, 1997).

Segundo Foucault (1999), esta normalização posicionaria a resistência política em um problema, pois não é recorrendo a soberania em oposição a disciplina que os efeito do poder disciplinar poderão se tornar limitados, visto que soberania e disciplina passaram a ser duas partes intrinsecamente constitutivas das práticas gerais do poder em nossa sociedade. Dada esta dificuldade, as forças que resistem ao biopoder passaram a se apoiar justamente naquilo sobre o que ele investe: na vida do ser humano. O que é reivindicado nas lutas sociais e serve de objetivo é a vida, compreendida como as necessidades fundamentais, a essência efetiva do humano, a realização de suas virtualidades. A vida tem sido caracterizada como objeto político e voltada contra o sistema que busca controlá-la. Muito mais do que o direito, a vida tem se tornado o objeto de embates políticos, mesmo sendo estes últimas formuladas por meio de afirmações de direito: direito à vida, ao corpo, à saúde, à auto-realização, à felicidade, à satisfação das necessidades, etc. "Esse direito, bastante incompreensível para o sistema jurídico clássico foi a réplica política a esses novos procedimentos de poder que, por sua vez, também não fazem parte do direito tradicional da soberania” (FOUCAULT, 1997, p. 136).

Foucault (1997) abandona em seus estudos o enfoque tradicional da noção de poder, ou seja, não faz mais uso do modelo de análise que considera o indivíduo como sujeito que possui direitos naturais e que tem como objetivo compreender a gênese do Estado, fazendo da lei a fundamental manifestação do poder. Ao invés de uma análise fundamentada em modelos jurídicos institucionais, Foucault (1997) direciona sua atenção nos modos concretos por meio do qual o poder penetra o corpo mesmo dos indivíduos e suas formas de vida. Em seus últimos anos, esta análise parece ter sido orientada por duas linhas de investigação diferentes: uma sendo o estudo das técnicas 
políticas por meio das quais o Estado assume e inclui o cuidado da vida natural dos indivíduos; e a outra o estudo das tecnologias do sujeito, mediante as quais o processo de subjetivação se efetua e que leva o indivíduo a vincular-se à própria identidade e, ao mesmo tempo, a um poder de controle exterior. Segundo Foucault (1997), o Estado ocidental moderno passaria a integrar técnicas de individuação subjetivas e procedimentos de totalização objetivos, fazendo com que surgisse um duplo vínculo político, constituído pela individuação e pela totalização simultânea das estruturas do poder moderno.

\section{A biopolítica e a gestão da vida nua humana - a figura do homo sacer}

Giorgio Agamben (1998) afirma que o ponto de convergência entre esses dois aspectos do poder permaneceu pouco explorado na investigação de Foucault. O filósofo italiano se pergunta onde estaria, no corpo do poder, a zona de indiferenciação ou, pelo menos, o ponto de intersecção em que se esbarram as técnicas de individualização e os procedimentos totalizantes. Indaga, enfim, se seria legítimo ou sequer possível manter a separação entre tecnologias subjetivas e técnicas políticas.

Através das investigações que compõem seu livro Homo sacer - o poder soberano e a vida nua, Agamben (1998) apresenta o que para ele é o ponto oculto no qual confluem o modelo jurídico-institucional e o modelo biopolítico do poder. Entre os pontos defendidos nesta obra, está a idéia de que essas duas análises não podem separarse e a afirmação de que as implicações daquilo que o autor chama de "vida nua" (natural, biológica) na esfera política constituem o núcleo originário, mesmo que velado, do poder soberano. Para Agamben (1998, p. 16), a biopolítica não é, portanto, conseqüência de uma transformação do poder soberano, mas o próprio “aporte originário do poder soberano. Ao situar a vida biológica no centro de seus cálculos, o Estado moderno não faz outra coisa além de voltar a dar luz ao vínculo secreto que une o poder com a vida nua".

Agamben (1998) recorre a uma figura do direito romano arcaico para mostrar como soberania e vida nua já se implicavam mutuamente, muito antes da modernidade. No direito romano arcaico, o homo sacer era o titular da vida nua (vida desqualificada), pois vivia excluído da polis e do direito. Essa condição de exclusão impedia o excluído de ser sacrificado aos deuses. No entanto, ele poderia ser morto por qualquer pessoa, 
sem que para isso houvesse punição. Ao se reportar à figura do homo sacer Agamben (1998, p.90) esclarece que aquilo que defina essa condição

Não é tanto a pretensa ambivalência originaria da sacralidade que lhe é inerente, quanto, sobretudo, o caráter particular da dupla exclusão em que se encontra preso e da violência à qual se encontra exposto. Esta violênciaa morte insancionável que qualquer um pode cometer em relação a ele não é classificável nem como sacrifício e nem como homicídio, nem como execução de uma condenação e nem como sacrilégio. Subtraindo-se às formas sancionadas dos direitos humanos e divino, ela abre uma esfera do agir humano que não é a do

O homo sacer é uma figura desprovida de direitos, um ser excluído da sociedade que pode ser morto impunemente, mas não pode jamais ser sacrificado aos deuses. A figura do homo sacer é utilizada por Agamben (1998) para retratar a vida nua, ou seja, uma vida desqualificada, desprovida de direitos, uma vida que não merece ser vivida.

Com o homo sacer, a vida humana se inclui na ordem religiosa e jurídica unicamente sob a forma de sua exclusão. A inclusão da vida por meio de sua exclusão faz com que participe de um estado de exceção. O estado de exceção, no qual a vida nua era, ao mesmo tempo, excluída da ordem jurídica e nela contida, constituía, segundo Aganbem (1998), o fundamento oculto sobre o qual repousava todo o sistema político. Ocorre, no entanto, que o espaço da vida nua, situada originariamente à margem da ordem jurídica, vai coincidindo progressivamente com o espaço político, de forma que exclusão e inclusão, externo e interno, zóé e bios ${ }^{t}$, direito e fato entram em uma zona de indiferenciação. $\mathrm{O}$ espaço que era juridicamente vazio no estado de exceção extrapola seus limites e passa a coincidir com a norma. Quando a exceção tende a converter-se em regra, estado de natureza e Estado de direito, vida e lei coincidem sem nenhum tipo de

¥ De acordo com Agamben (1998), na Antiguidade clássica, os gregos (e esta é uma caracterotica desde os prim?dios da civilização ocidental presente até nossos dias, a indeterminação conceitual da vida), qualificavam as formas-de-vida basicamente em dois níeis Zoe e Bios. A característica da primeira forma de vida, a Zoe, era o fato de procurar representar a vida em sua totalidade. Vida animal, vida humana e, vida dos deuses e, mais especificamente do ponto de vista da Polis, era a vida prória dos escravos, dos comerciantes, das mulheres e das crian?s em sua proximidade e vinculado com a vida bioltiica. Portanto, a Zoe apresentava-se como vida desqualificada na perspectiva da Polis, forma-de-vida que estava sob os cuidados do poder dom?tico exercido pelo Pater. A Bios designava a forma-de-vida de um indiv?uo, de um grupo; era a vida qualificada do cidadão em sua participação na política da polis, dos debates políticos. Era assim, portadora de direitos e deveres politicos e, reconhecida nesta condição como meio para o alcance da felicidade, do bem viver.

RPI Revista de Pesquisa Interdisciplinar, Cajazeiras, v. 1, n. 1, 33-46, jan/jul. de 2017. 
distinção. Quando as fronteiras do estado de exceção se desmancham e se fazem indeterminadas, a vida nua, específica, que ali habitava fica liberada em toda parte e passa a ser ao mesmo tempo o sujeito e o objeto do ordenamento político e de seus conflitos, o lugar único tanto da organização do poder estatal como da emancipação dele.

A transformação da vida em sujeito e objeto da política talvez possa ser explicada pelo fato de que, simultaneamente ao processo disciplinar, através do qual o poder estatal faz do humano enquanto ser vivo o próprio objeto do poder, ocorreu o próprio nascimento da democracia moderna, na qual o humano em sua condição de vivente já não se apresenta como objeto senão como sujeito do poder político. Estes dois processos, opostos e aparentemente conflitivos em vários aspectos, convergem, porém, no fato de que nos dois o que está em questão é a vida nua do cidadão, que passou a ser nada menos que o novo corpo biopolítico da humanidade (AGAMBEM, 1998).

O homo sacer é insacrificável e, no entanto, qualquer um pode matá-lo. A vida nua à qual se refere a violência soberana remete a uma idéia de sacralidade que já não pode definir-se por completo através de sua adequação para o sacrifício ou de sua relação com rituais de imolação. Na modernidade, sugere Agamben (1998) o princípio da sacralidade da vida se emancipou por completo da noção de sacrifício. O significado do termo sagrado em nossa cultura prolonga a história semântica do homo sacer e não a do sacrifício religioso. A vida cada vez mais se expõe a uma violência sem precedentes, mas que se manifesta nas formas mais profanas e banais.

Nos dois casos, estas transposições se produziram em contextos onde a política já havia se transformado em biopolítica e nos quais o que estava em jogo consistia já exclusivamente em determinar que forma de organização resultaria mais eficaz para assegurar o cuidado, o controle e o desfrute da vida nua. A diferença está apenas no fato de que uma mesma reivindicação da vida nua conduz, nas democracias burguesas, ao primado do privado sobre o público e das liberdades individuais sobre as obrigações coletivas.

Cabe destacar que o aspecto central da abordagem empreendida por Aganbem (2004), no que concerne à biopolítica, é a identificação de uma estrutura jurídica, que existe desde a gênese da experiência política ocidental, relacionando direito e vida, ou seja, a existência de um poder soberano e de um estado de exceção que se torna regra na modernidade, capaz de tomar a vida em seu aspecto mais elementar: a nudez da vida 
sem qualquer direito político, ou um corpo biológico "à mercê” (abandonado) do poder soberano

Transforma, assim, a totalidade da vida num objeto de gerenciamento do Estado; otimiza as potencialidades vitais e deixa morrer, de acordo com os cálculos de custo benefício estabelecidos pela dinâmica determinante das relações vitais produtivas e de consumo (ASSMANN; BAZZANELLA, 2012, p. 8).

Portanto, entre a esfera da vida nua e a esfera do jurídico-institucional existe um vínculo que frequentemente permanece oculto. Mas esses dois âmbitos de análise não podem ser separados, haja vista que "a implicação da vida nua na esfera política constitui o núcleo originário - ainda que encoberto - do poder soberano" (AGAMBEN, 1998, p. 14).

Pode-se aqui, dizer, nos termos de Agamben (1998), que as mulheres em estado de violência seriam um Homo Sacer de hoje, privadas da humanidade completa assim como os escravos que eram constituídos como Homo Sacer, já que, apesar de serem humanos vivos, eram excluídos da comunidade política.

Seria possível considerar a vida da mulher que sofre violência como aquela do homem sacro? A vida nua corresponde ao indivíduo, que apresenta alguma característica peculiar (religião, nacionalidade, etc), e esta característica fez com que perdesse seus direitos de proteção dado pelo Estado, ou seja, sua cidadania, e por isso é uma vida matável. Pode-se citar como exemplo de um de seus personagens, as mulheres vítimas de violência doméstica, porque seus maridos ou ex-maridos se julgam no direito de lhes tirar a vida, e muitas mulheres já foram assassinadas em decorrência deste tipo de violência.

Parece que existem inúmeras situações que exemplificam esse conceito de vida nua no mundo contemporâneo. Pode-se evidenciar esse cenário atual com um exemplo que parece ser bastante pertinente nos dias de hoje: o machismo. Em muitos casos, após o matrimônio ou quando o casal se junta para morar na mesma casa, a mulher fica em sua habitação para realizar as atividades domésticas (lavar roupa, limpar a casa, fazer comida, cuidar dos filhos, etc.), enquanto o homem trabalha fora para arrecadar dinheiro para o sustento da família. Ele então se torna o chefe da família, por sua tarefa ser a mais ligada à economia, e o trabalho da mulher é totalmente desprezado por não gerar 
lucros. Infelizmente, isso deu mais sustentação para a sociedade patriarcal e por consequência a violência doméstica.

Nesse sentido, a mulher, na visão machista, poderia ser vista como um ótimo exemplo de vida nua, uma vez que o machismo perpetua um pensamento que enxerga as mulheres como objeto, inferiores, submissas aos homens e que devem estar sempre dispostas a agradá-los. Ou seja, um ser humano privado de sua bios, que é onde está a consciência política, O machismo consegue parece caracterizar as mulheres como Homo Sacer, ou seja, o homem insacrificável, que perde seus direitos materiais e terrestres, visto que em algumas culturas, uma mulher que não se submeter aos desejos de um homem (sendo ele seu companheiro ou não) está sujeita a receber castigos severos, podendo vir a correr risco de vida. Essas culturas tornam-se verdadeiros campos de concentração para grupos oprimidos e marginalizados (que não se restringem ao de mulheres), o que Agambem (1998) considera a regulamentação da vida nua, ou seja, a transformação a exceção em regra.

\title{
Mulheres renegadas - violência, exclusão social e vulnerabilidade
}

\author{
"Nosso corpo como flagelo, nossa alma como \\ lixo" (Ministra Cármen Lúcia, vice- \\ presidente do STF ao comentar sobre o \\ estupro coletivo sofrido por uma \\ garota de 16 anos, no Rio $)^{\S}$.
}

A violência não pode ser entendida apenas como uma ação física, mas também uma ação moral, podendo esta ser percebida através do processo de exclusão social a que muitos estão submetidos. A mulher, por ser considerada uma minoria, é alvo constante dessas ações. Dentro de um contexto de exclusão social, aliado as situações de violência, observam-se claramente diferenciações dessas manifestações quando da análise das questões envolvendo gênero. Dessa forma, nota-se a perpetuação de estigmas que colocam o homem como ser superior, sendo a mulher subjugada e alvo de preconceito.

\footnotetext{
${ }^{\S}$ http://www.oantagonista.com/posts/carmen-lucia-nosso-corpo-como-flagelo-nossaalma-como-lixo/
}

RPI Revista de Pesquisa Interdisciplinar, Cajazeiras, v. 1, n. 1, 33-46, jan/jul. de 2017. 
Segundo Bauman (2005), fenômenos como o da população em situação de exclusão, ocorrem não por uma falha do sistema capitalista, mas pela sua própria lógica de funcionamento, que se baseia na produção de excessos, tanto materiais quanto humanos. Com isso, um enorme contingente populacional torna-se aquilo que Bauman (2005) denomina como "refugo humano", que, em algum momento, é considerado descartável. Nas palavras do autor:

A produção de "refugo humano", ou, mais propriamente, de seres humanos refugados (os "excessivos" e "redundantes", ou seja, os que não puderam ou não quiseram ser reconhecidos ou obter permissão para ficar), é um produto inevitável da modernização, e um acompanhante inseparável da modernidade. É um inescapável efeito colateral da construção da ordem (cada ordem define algumas parcelas da população como "deslocadas", "inaptas" ou "indesejáveis") e do progresso econômico (que não pode ocorrer sem degradar e desvalorizar os modos anteriormente efetivos de "ganhar a vida" e que, portanto, não consegue senão privar seus praticantes dos meios de subsistência) (BAUMAN, 2005, p. 12).

Essa concepção de refugo humano de Bauman dialoga com a ideia de "descarte", trabalhada por Melazzo e Guimarães (2010), segundo os quais existem dois tipos de descarte: o de resíduos sólidos e o da pessoa humana, que já não são necessários para a sociedade, pelo menos por um período, e dos quais esta não quer mais cuidar.

A despeito das especificidades e heterogeneidade que caracterizam a população em situação de exclusão, conforme mencionado acima, parte dos "refugos humanos" produzidos pelo sistema capitalista - a opressão, a invisibilidade e a violência física e simbólica marcam as suas trajetórias de vida como um todo, as quais, em geral, são ainda reforçadas por outras exclusões, multidimensionais e socialmente compartilhadas, ligadas às questões de gênero, classe, raça, idade e orientação sexual.

Nesse contexto, os problemas vividos por mulheres em situação de violência há algum tempo tem sido recorrentemente suscitados. São relatados fatos concretos de violações de direitos dessas mulheres, que se verificam no modo como sofrem intensamente as condições sociais impostas e estabelecidas, seja no ambiente domestico, bem como pelas instituições, que as tornam "invisíveis" e negligenciadas diante de suas necessidades específicas. Assim, é possível afirmar que muitas mulheres estão renegadas à de refugo humano - a partir do conceito de Bauman (2005).

As mulheres compõem de modo relevante o número de pessoas que vivem em situação de violência. Elas sofrem de maneira ainda mais acentuada com as invisibilidades e as violências físicas e simbólicas, destacando-se as violações que 
detêm expressivos recortes de gênero. A desvalorização em função da condição de gênero se expressa na postura de subalternidade no trabalho, no relacionamento com o parceiro e na banalização da violência sofrida que poderia caracterizá-la como refugo humano, que nada mais é do que um "efeito colateral da construção da ordem, cada ordem define algumas parcelas da população como deslocadas, inaptas ou indesejáveis" (BAUMAN, 2005, p. 12).

A Declaração Universal dos Direitos Humanos diz que nenhum ser humano deve sofrer tratamento degradante, cruel ou desumano. É importante ter presente que os direitos humanos são o resultado de lutas e embates políticos e estão sujeitos a avanços e retrocessos. Por esta razão observamos que, ao longo da história, e ainda hoje, determinadas classes e grupos sociais tem sido relegados a cidadãos de segunda categoria com menor acesso aos direitos vigentes naquela sociedade, seja em seu aspecto normativo seja em seu exercício. (PIOVESAN, 2008).

As mulheres, ao longo dos séculos, têm sido privadas do exercício pleno de direitos humanos e têm sido submetidas a abusos e violências, tanto em situações de guerra, como no espaço da vida familiar e doméstica, elas têm tido um papel de grande relevância na ampliação do alcance dos direitos humanos. Questões que sempre fizeram parte da sua agenda, como a violência doméstica, os direitos sexuais e reprodutivos, direitos sociais específicos à mulher, a violação de sua integridade física, entre outros temas, vêm sendo colocadas por esses movimentos nas pautas de discussões das Nações Unidas e no âmbito nacional. As mulheres têm sido protagonistas nessa trajetória (PIOVESAN, 2008).

\section{Atuação biopolítica contemporânea: a lei do feminicídio}

No dia nove de Março de 2015 foi sancionada pela Presidente Dilma Rousseff a lei $\mathrm{n}^{\circ} 13.104$ - lei do feminicídio. Essa lei criou como modalidade de homicídio qualificado, o feminicídio, aquele que ocorre quando uma mulher é morta por razões de sua condição de sexo feminino. A nova lei acrescentou ao $\S 2^{\circ}$-A uma explicação do termo "razões da condição de sexo feminino", o qual ocorrerá em duas hipóteses: a primeira no caso de violência doméstica e familiar, e a segunda, menosprezo ou discriminação à condição de mulher. A lei acrescentou ainda o $\S 7^{\circ}$ ao art. 121 do Código Penal estabelecendo causas de aumento de pena para o crime de feminicídio. A pena será aumentada de $1 / 3$ até a metade se for praticado durante a gravidez ou nos 3

RPI Revista de Pesquisa Interdisciplinar, Cajazeiras, v. 1, n. 1, 33-46, jan/jul. de 2017. 
meses posteriores ao parto; contra pessoa menor de 14 anos, maior de 60 anos ou com deficiência e na presença de ascendente ou descendente da vítima. (GRECO, 2015).

Contudo, ás condições para aplicação ao caso de violência doméstica:

Art. $5^{\circ}$ Para os efeitos desta Lei,configura violência doméstica e familiar contra a mulher qualquer ação ou omissão baseada no gênero que lhe cause morte, lesão, sofrimento físico, sexual ou psicológico e dano moral ou patrimonial: I - no âmbito da unidade doméstica, compreendida como o espaço de convívio permanente de pessoas, com ou sem vínculo familiar, inclusive as esporadicamente agregadas; II - no âmbito da família, compreendida como a comunidade formada por indivíduos que são ou se consideram aparentados, unidos por laços naturais, por afinidade ou por vontade expressa; III - em qualquer relação íntima de afeto, na qual o agressor conviva ou tenha convivido com a ofendida, independentemente de coabitação (BRASIL, 2015).

Dessa forma, é notável a atenção que a lei oferece ao caso de violência doméstica, isso ocorre porque, segundo Mello (2015, p.3)

Enquanto o homem sofre com a violência ocorrida no espaço público que, via de regra, é praticada por outro homem, a mulher sofre mais com a violência ocorrida no espaço privado e os agressores são (ou foram) namorados ou maridos/companheiros.

E para concluir as alterações feitas pela Lei do feminicídio, foi alterada a Lei de crimes hediondos, esclarecendo que o feminicídio é uma nova modalidade de homicídio, acrescentando, por tanto, ao rol de crimes hediondos.

Com a entrada da Lei 13.104/2015 o legislador resolveu qualificar o crime, na relação entre mulheres heterossexual ou transexual (sexo biológico não correspondente à identidade de gênero; sexo masculino e identidade de gênero feminina), caso haja violência baseada no gênero, pode caracterizar o feminicídio. Para Teles e Melo (2002) a violência de gênero representa uma relação de poder de dominação do homem e de submissão da mulher. Demonstra que os papéis impostos às mulheres e aos homens, consolidados ao longo da história e reforçados pelo patriarcado e sua ideologia, induzem relações violentas entre os sexos.

Por fim, é importante ressaltar como afirmam Teles e Melo (2002) que a lei do feminicídio veio abranger as mulheres assassinadas pela sua condição de mulher, 
vítimas de um preconceito abusivo. Assim, é valido ressaltar os avanços que a lei pretende gerar a partir de seus efeitos jurídicos e sociais, sendo esses a redução dos homicídios e maior atenção e proteção às mulheres.

\section{Considerações finais}

Concluímos que tanto a teoria biopolitica de Foucault quanto a de Agambem podem ser utilizadas como importantes instrumentos de análise da problemática da violência contra a mulher na atualidade, importando em novas formas de abordagem e compreensão do tema. A luta contra essa categoria ao exigir uma ação pedagógica e uma tomada de consciência de sua gravidade, pode se valer do que as propostas de Foucault e Agambem têm a contribuir.

A constatação de que o Estado age biopoliticamente é um importante passo para o início da luta contra qualquer forma de violência que possa ser infligida ás mulheres. Essa preocupação é cara especialmente ao jurista, haja vista que o direito consubstancia relevante veículo dessas sujeições. $\mathrm{O}$ estudo das estratégias de normalização não pode escapar do pensador do direito, tendo em vista que se de um lado o saber jurídico tradicional ainda leva em conta o "sujeito de direito" envolto por categorias artificiais (autonomia da vontade, interesse, igualdade etc.), de outro o sujeito real revela-se cada vez menos autônomo, política e intelectualmente, e cercado por tecnologias que o tornam controlado, disciplinado, normalizado.

\section{Referências}

AGAMBEN, Giorgio. Homo sacer: o poder soberano e a vida nua. Tradução de Henrique Burigo, Belo Horizonte: Editora da UFMG, 1998.

Profanações. São Paulo: Boitempo, 2007.

BAUMAN, Z. (2005). Vidas desperdiçadas. Rio de Janeiro: Zahar.

BRASIL. Código Penal. Disponível em: http://www.planalto.gov.br/ccivil_03 / decreto-lei/del2848.htm (consultado em 15/06/2016).

FOUCAULT, Michel. História da sexualidade 1: a vontade de saber. Rio de Janeiro: Graal, 1997. 
Michel. Soberania e disciplina. In: FOUCAULT, Michel. Microfísica do poder. Rio de Janeiro: Graal, 1999.

GARCIA, Leila Posenato, et al. : feminicídios no Brasil. Disponível em: <http://www.ipea.gov.br/portal/images/stories/PDFs/

130925_sum_estudo_feminicidio_leilagarcia.pdf>. Acesso em 11/06/2016.

GRECO, R.; Feminicidio comentários sobre a lei $\mathbf{n}^{\circ}$ 13.104, de 9 de março de 2915. Disponível: http://www.rogeriogreco.com.br/?p=2906 Acessado em 11 de junho de 2016.

MELAZZO, E. V., \& Guimarães, R. B. Ponto de partida: a desigualdade social e a definição da política urbana. In. E. V. Melazzo \& R. B. Guimarães (Orgs.). Exclusão social em cidades brasileiras: um desafio para as políticas públicas. (pp. 11-31). São Paulo: UNESP.

MELlO, A. R. Feminicídio: uma analise sócio-jurídica do fenômeno no Brasil. Disponível:

http://www.compromissoeatitude.org.br/wpcontent/uploads/2013/07/ADRIANARAMO SDEMELLO_FEMICIDIO.pdf Acessado em 11 de junho de 2016.

PIOVESAN, Flávia e IKAWA, Daniela, coordenadoras. Direitos humanos: fundamento, proteção e implementação. Curitiba: Juruá. vol. 2. 2008.

SOUZA, Sérgio Ricardo de. Comentários à lei de combate à violência contra a mulher. Curitiba: Juruá. 2007

PASINATO, Wânia. "Femicídios" e as mortes de mulheres no Brasil. Cad. Pagu, nº.37, Campinas July/Dec. 2011 Disponível em: . Acesso em: 15 junho. 2016.

TELES, Maria Amélia de Almeida. O que é violência contra a mulher /Maria Amélia de Almeida Teles, Mônica de Melo. São Paulo: Brasiliense, 2002.

RPI Revista de Pesquisa Interdisciplinar, Cajazeiras, v. 1, n. 1, 33-46, jan/jul. de 2017. 